\title{
Tampopo: un análisis fílmico de carácter gastronómico
}

\author{
Tampopo | Juzō Itami | 1985 \\ José Javier Santana González*, María José Molina García y Carmen Enrique Mirón \\ Universidad de Granada, España
}

Recibido: 26 febrero 2020; aceptado: 6 de abril 2020

\begin{abstract}
Resumen
El objetivo de este trabajo es analizar un texto fílmico para comprender las relaciones entre cine y cultura expresadas en la gastronomía y la alimentación. Para ello analizaremos desde una perspectiva empírico-analítica la película Tampopo (1985) dirigida por Juzo Itami y que refleja las diferentes categorías en las que se divide el llamado cine gastronómico, así como la utilización de ejemplos de otros filmes que también pueden entenderse como gastronómicos, en un intento por comprender si realmente existe dicho género o simplemente si el cine ha utilizado la gastronomía como hilo conductor y sin una intención real de reflejar la cultura de un determinado lugar en sus formas gastronómicas.
\end{abstract}

Palabras clave: Cine | Cultura | Gastronomía | Alimentación

Tampopo: a filmic-gastronomic analysis

Abstract

The objective of this work is to analyze a filmic text to understand the relationships between cinema and culture expressed in gastronomy and food. For this we will analyze from an empirical-analytical perspective the film Tampopo (1985) directed by Juzo Itami and that reflects the different categories in which the so-called gastronomic cinema is divided, as well as the use of examples from other films that can also be understood as gastronomic, in an attempt to understand if this genre really exists or simply the cinema has used gastronomy as a common thread and without a real intention to reflect the culture of a particular place in it's gastronomic forms.

Keywords: Film | Culture | Gastronomy | Feeding

En el siglo XX el cine ha servido como herramienta para representar audiovisualmente conflictos que atañen a las relaciones de identidad y cultura, habida cuenta de que es una de las formas más sencillas de llegar a un gran número de público (Goyeneche, 2012). Tal y como señaló Marc Ferro en 1991 las personas pasan más tiempo mirando la televisión o yendo al cine que leyendo libros, y eso hace que la manera de entender las cosas y de aprenderlas esté cada vez más ligada a métodos audiovisuales. Será Ferro (1995) quien considere el carácter de fuente informativa en este tipo de trabajos porque "el film se observa no como obra de arte, sino como un producto, una imagen objeto cuya significación va más allá de lo puramente cinematográfico; no cuenta solo por aquello que atestigua, sino por el acercamiento sociohistórico que permite" (p. 39). Pese a que Marc Ferro se refería más a la relación entre cine e historia, en este trabajo conjugaremos cine con gastronomía y nos resulta igual de efectiva su afirmación, aunque es conveniente tomar más íntegramente la definición de David Bordwell (1996) quien supone que "todo filme está inscrito en un canon histórico de representación, que posee sus propias reglas y formas" (p. 390). Atendiendo a esta unión cine-gastronomía, recurriremos a la idea de que hablar de gastronomía es aunar los términos de alimentación y cultura en uno solo (De Garine, 1998) y a sistemas culturales distintos, corresponden también sistemas alimentarios diferentes (Contreras y Gracia, 2005).

El auge de la antropología alimentaria, identificado en un aumento de los trabajos sobre alimentación y en la investigación gastronómica, y apoyado en la introducción de nuevas asignaturas en carreras universitarias; la creación de nuevos grupos de investigación con soporte institucional; y el incremento de las publicaciones cientí-

* Corresponding author: jjsantanagonzalez@gmail.com 
ficas (Gracia, 2010), ha dado lugar al aumento unilateral del cine basado en la alimentación y éste se ha ido adaptando a lo largo de la historia a los diferentes discursos culturales y a las diferentes visiones que el espectador adquiere de la manera de ver y entender el cine (Hidalgo, Segarra y Rodríguez, 2016).

Aunque los defensores del género de cine gastronómico son muchos (Hidalgo et al., 2016) y ponen en valor la amplia creación de este cine que se está llevando a cabo desde hace unas décadas, la crítica general aún no se pone de acuerdo en establecer dicha clase fílmica (Bote, 2011) y reprocha la falta de importancia que se les priva a algunas temáticas como la escasez de alimento y el hambre (Hidalgo et al., 2014). Según Casetti (2000) la importancia del género en el cine no surgió hasta la década de los setenta del pasado siglo, cuando los diferentes espacios en los que se engloba el cine son detectables por el espectador y hay una repetición de los esquemas narrativos. Lo que se pretende con la introducción de los géneros es la simplificación de la descodificación del cine, para que el público pueda captar, con mayor facilidad, la exposición de la obra. Por otra parte, en el siglo XXI se produce un auge de cine gastronómico, que viene de antiguo, puesto que desde los años ochenta están creando relatos fílmicos que tienen a la gastronomía como elemento de arraigo del sujeto a su propio contexto (Hidalgo et al., 2016) y se ha convertido, por tanto, en una manifestación sólida internacionalmente como fenómeno de la cultura contemporánea, tal y como cita Hidalgo et al. (2014) del libro de Marjorie Ross, Los siete pasos de la danza del comer: "la cultura culinaria es un sistema de símbolos, expresión de las estructuras más inconscientes de cada pueblo, por medio del cual le otorgamos significado a nuestra propia existencia” (p. 2).

Existen tres categorías dentro de este género cinematográfico (Hidalgo et al., 2014):

La comida como reflejo de la diferenciación social, a la que pertenecerían títulos como El discreto encanto de la burguesía (1972) de Luis Buñuel, donde se muestra la forma idónea de beberse un Martini, siguiendo unas reglas concretas cuando asiste al modo vulgar de hacerlo uno de los personajes, engulléndolo de un trago; otro ejemplo es Tiempos modernos (1936) de Charles Chaplin, una de las mejores muestras de esta categoría, en ella se refleja perfectamente el hecho de la diferenciación social, a lo largo de toda la cinta, siendo uno de los ejemplos más ilustrativos, cuando el jefe del protagonista consigue un nuevo invento que acortaría los tiempos del almuerzo de sus trabajadores, al que denomina "automatizador de almuerzo"; un tercer ejemplo es El festín de Babette (1987) de Gabriel Axel, donde la protagonista, Babette, gana la lotería e invita a todo el pueblo a un festín de delicias provenientes de Francia como señal de estatus social.

La comida como exaltación de los sentimientos, con películas como Comer, beber, amar (1994) de Ang Lee, donde son continuos los símiles entre la comida y la vida, puesto que para el protagonista vivir día a día es lo mismo que cocinar, priorizando el sabor frente a los ingredientes, es decir, realiza una metáfora acerca de la adversidad frente a los problemas cotidianos; Como agua para chocolate (1992) de Alfonso Arau, donde vemos a una Rosaura triste por no haber logrado casarse con el hombre al que amaba, y a su asistenta que le lleva un trozo de pan para comer asegurando que las penas con pan son menos; El gran chef (2007) de Jeon Yun-Su, en la que se cuenta la historia de una disputa histórica entre familias de grandes chefs japoneses a raíz de un torneo para el que el protagonista tiene que sacrificar a su animal de compañía, una vaca, que fue lo único que le quedó cuando su casa fue destruida. Sacrificar su res para él es similar a sacrificar a su hermana.

La representación de la profesionalidad gastronómica, donde se encuadran cintas como Julie E Julia (2009) de Nora Ephron, en la que Liz, la protagonista, viaja a diferentes países y comienza a relacionar momentos y personas con platos típicos de los lugares que visita; Ratatonille (2007), de Brad Bird, que comienza con un anuncio publicitario donde puede leerse que "a cada uno de los países del mundo le gustaría poder disputar este hecho, nosotros los franceses sabemos la verdad: la mejor comida del mundo se hace en Francia"; o Tampopo, que analizamos a continuación.

Si nos centramos en esta clasificación, Tampopo (1985) de Juzo Itami, pertenecería a la representación de la profesionalidad gastronómica tal y como hemos anunciado, puesto que la protagonista es la regente de un local de fideos japoneses y el argumento gira en torno a ella, aunque realmente se detecta que engloba, en diferentes partes de la película, a las tres clasificaciones cinematográficas a las que nos hemos referido.

Este trabajo analiza la película desde una perspectiva empírico analítica de tipo ex-post-facto, transversal, exploratoria y descriptiva, utilizando un instrumento ad 
hoc basado en los de Aguirre y Alberich (2014) y Cobo (2015) mediante el cual se han obtenido datos acerca del quién, cómo, dónde y por qué de los elementos culturales, gastronómicos y cinematográficos. Todos estos datos han sido analizados mediante el paquete SPSS, en su versión 24 para MAC, complementado con un análisis interpretativo de perspectiva cualitativa.

Desde el principio, la película se ve sumida en el aspecto gastronómico. Así, al inicio, un hombre entra en un cine, se sienta en la primera fila y sus sirvientes le abren una mesa y le ponen algún tipo de comida y pan. El personaje expone un pequeño monólogo sobre la gente que va al cine a hacer ruido abriendo bolsas de plástico, hecho claramente vinculado a la diferenciación social, junto con el cliché de comer en los cines, mientras se visualiza una película, componente cultural arraigado en la sociedad de masas.

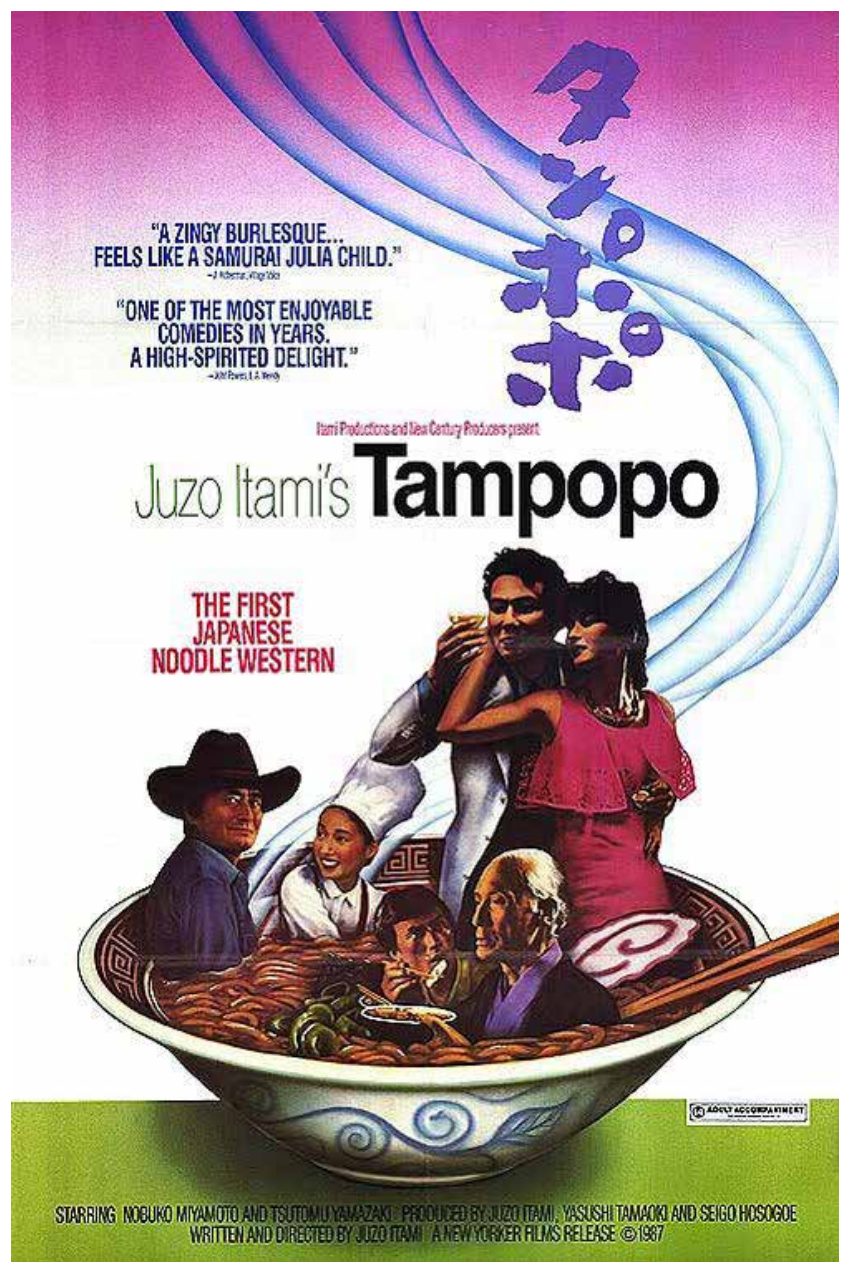

La exaltación de los sentimientos será recurrente a lo largo de la película otorgándole casi un componente místico. En una de las escenas se muestra a un maestro que lleva estudiando durante cuarenta años la mejor manera de comer fideos, y a su pupilo, a quien da las siguientes indicaciones:

1. Observar el cuenco rebosante (apreciando la armonía del conjunto, percibiendo el aroma y analizando los ingredientes).

2. Acariciar la superficie con la punta de los palillos (para demostrar afecto al plato).

3. Posteriormente, añadir la carne de cerdo, sumergiéndolo en la sopa a la derecha del cuenco, pues lo importante de este paso es disculpar al cerdo como diciéndole "te veo luego".

4. Comenzar a comer primero los tallarines y, mientras se saborean, mirar la carne de cerdo con afecto.

Si pensamos en un plato típico japonés, pensamos en los fideos servidos con sopa. De hecho, en los últimos años son innumerables los anuncios que intentan vender fideos instantáneos o ramen tipo japonés, fruto de la globalización comercial y la mundialización de ciertos productos que son distintivos de una determinada cultura. Tanto es así que esta película marcó un hito dentro de la cultura y el cine japonés, pues hubo un aumento de los establecimientos de venta de ramen. Siguiendo la idea de los fideos como plato representativo de la cultura japonesa y que la película no hace sino aumentar la devoción por ellos, en una escena del filme vemos a dos de los protagonistas entrando en el local de fideos de Tampopo, y uno de ellos presiente un mal augurio porque Tampopo está cocinando los fideos en agua aún sin hervir. Este augurio se transforma en una pelea multitudinaria en el local. Por tanto, la idea de misticismo en torno a los fideos está muy presente en toda la película: no debemos olvidar que se trata de una comedia y que el hilo conductor es el hecho gastronómico, es decir, lo que referíamos al principio sobre la idea de la unión de la comida y la cultura (gastronomía) con tintes de comedia.

La película está dividida en la historia principal, que sigue una introducción, un nudo y un desenlace, sin embargo, también contiene pequeños gags que nada tienen que ver con la idea principal del film. En uno de estos momentos, se ve a un grupo de hombres muy trajeados, probablemente altos ejecutivos, que van a almorzar a un sitio famoso por su marisco. Uno de estos hombres lleva a un ayudante, un chico muy joven. Cuando van a sentarse a la mesa, los hombres se van disponiendo en orden de edad, siendo el ayudante el último en sentarse por ser el menor. Por respeto, se les ofrece a los mayores de la 
mesa pedir los primeros, pero, puesto que aún están eligiendo su plato, el camarero se ofrece a otros comensales. El primero de ellos pide Lenguado Menieure, consomé y para beber cerveza Heineken. Los demás piden lo mismo que el primero (mostrando falta de saber gastronómico). El chico más joven entabla conversación con el camarero y le dice que las croquetas al estilo Boudin, son típicas de Taille-Vent (Francia), a lo que el camarero responde que el cocinero aprendió a cocinar allí. Pide las croquetas y además caracoles con setas cocidos en vino de Madeira, una ensalada de manzana y nueces, y para beber un Corton-Charlemagen de 1981. Los demás comensales miran al chico con cara de incredulidad. Esta escena es muy representativa del auge que la gastronomía ha tenido a lo largo de las últimas décadas, pues si bien la película es de 1985 ya encontramos arraigada la idea de que la comida de calidad, o que se ingiere en ocasiones especiales, tiene que ser de alta calidad, y sin duda esta comida es la francesa. Se deja de lado el misticismo de los fideos japoneses tradicionales, para dar paso a una comida moderna que debe ser acompañada de una bebida hecha a medida; en este caso el menor de los hombres es quien entiende el maridaje entre comida-bebida, y los demás comensales tienden a pedir una cerveza europea como es Heineken, que era la cerveza de moda en la década de los ochenta.

La popularización de la comida francesa como la dominante en el mundo por su calidad, es en parte producto del cine donde encontramos multitud de referencias como en Chocolat, donde un pueblo de la campiña francesa asemejaba la ingesta de dulce con el diablo; en la ya citada Ratatonille, ambientada en un plato típico francés y donde el estereotipo de Francia como cuna de la comida perfecta lo encontramos a lo largo de toda la película, de hecho nada más comenzar una voz en off, apunta: "Aunque a cada uno de los países del mundo le gustaría poder disputar este hecho, nosotros los franceses sabemos la verdad: la mejor comida del mundo se hace en Francia"; y en Tampopo hallamos referencias directas a Francia, así en una de las escenas Tampopo va a consultar a un maestro cocinero sobre la cocción de los fideos, mientras este imparte clases de cocina a unos vagabundos y define la cocina francesa como una constante lucha contra los fogones, acto seguido le prepara al hijo de Tampopo una tortilla con arroz y tomate. De este modo, además de las referencias a Francia, que expresan la representación de la profesionalidad gastronómica, contamos con una referencia cultural representada en una receta que difiere según dónde se prepare. Encontramos la tortilla a la francesa con arroz y tomate (el tomate va dentro de la tortilla) y la tortilla con arroz y tomate (donde el tomate se dispone encima de la tortilla).

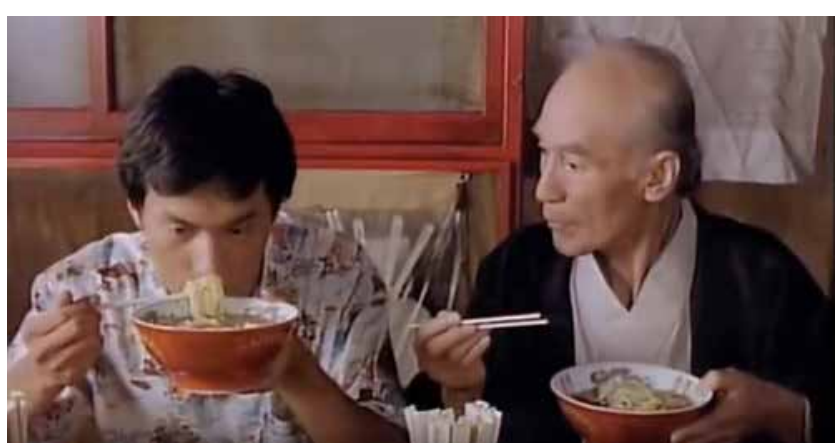

Fotograma de la película Tampopo

Las referencias culturales en Tampopo no son meras alusiones a la cocina moderna o la nouvelle cuisine, también otorga especial atención a la tradición histórica de un plato típico japonés, el Suppon ${ }^{1}$, que, a su vez, tiene gran importancia en Brasil, aunque en este país se realiza con otra tortuga, debido a la gran población inmigrante japonesa producto de la crisis demográfica en el país nipón a comienzos del siglo XX y la falta de mano de obra para las plantaciones de café en tierras caribeñas, que favorecieron el intercambio cultural.

Las tres categorías en las que nos basamos son sometidas a revisión en Tampopo y podemos entender que deberían ser ampliadas con una cuarta categoría que sería la representación del erotismo en la gastronomía, reflejada en la película con una escena que transcurre en la playa, donde dos desconocidos están recogiendo ostras (está ya inmerso en el imaginario popular la idea de que las ostras son afrodisíacas) y acaban besándose. Por tanto, a la clasificación que hemos visto anteriormente le añadimos la nueva categoría denominada erotismo en la gastronomía, que aunaría las ideas de alimentos afrodisíacos y la comida como placer. Otro ejemplo de esta categoría sería, además de Tampopo, La gran comilona (1973) de Marco Ferreri. En ella un grupo de amigos quedan para comer hasta morir. Una de las escenas de la película representa muy bien esta nueva categorización, en ella aparece el grupo de amigos compitiendo por ver quién come más ostras mientras catalogan fotos de mujeres desnudas como sentimentales o artísticas. En otro de los momentos de la película, uno de los protagonistas aparece comiendo junto a una prostituta semidesnuda al lado de su coche, un bugatti de carreras, todo ello como una representación de los placeres: la comida, el sexo y la velocidad. Otro ejemplo que podemos destacar en esta categoría es Deliciosa Martha (Nettlebek, 2011), esta cinta 
muestra una escena donde la protagonista, Martha, juega con otro chef a degustar platos con los ojos vendados. La escena está acompañada de una gran carga de erotismo, donde los ingredientes se mezclan con apasionados besos.

Finalmente, la protagonista de Tampopo, que da nombre al título de la cinta, consigue convertirse en una gran chef de fideos y estrena un nuevo local. En la escena final, su maestro le dice: "nunca pensé que una mujer llegara a ser una buena cocinera de tallarines", esto es otro elemento cultural y de tintes machistas que aún hoy forma parte de la sociedad. En la ya citada Deliciosa Martha, encontramos otra referencia al inicio de la película cuando un cliente del restaurante donde trabaja Martha, exige ver al chef, al verla a ella el cliente espeta "ahora lo entiendo todo". El concepto de la mujer como cocinera profesional (la profesionalidad gastronómica de nuestra clasificación) no está tan extendido, pero sin embargo está normalizado que la mujer se ocupe de la cocina doméstica, que en estos filmes gastronómicos son entendidos como la cocina con amor (lo que nosotros identificamos con la exaltación de los sentimientos), con lo cual, equiparamos con la figura de gran chef a un varón, y con la figura de cocina tradicional a la figura femenina, que, a la postre, es a lo que se refiere la frase citada que le dicen a Tampopo.

Este breve análisis sobre el nacimiento de la unión entre cine y gastronomía tiene su punto de partida en la idea de Santamaría (2016) quien nos indica que la efímera gastronomía apoya este carácter fugaz en el cine, como arte del tiempo y del espacio y ello ha llevado a crear un boom, no solo cinematográfico, sino cotidiano que lleva a la televisión la cultura de la alimentación, representado en los múltiples programas culinarios que se emiten a diario, e incluso a la cotidianeidad de las redes sociales, donde encontramos infinidad de videos cortos mostrando recetas, así como páginas de recetas y técnicas culinarias, con lo que fácilmente podemos mostrar qué, cuándo y cómo ingerimos un alimento (García, 2014).

\section{Referencias}

Aguirre, M. y Alberich, J. (2014). Cambios en el documental de naturaleza televisivo en España. De Félix Rodríguez de la Fuente a Frank Cuesta (1974-2011). Comunicación Vivat Academia, 130, 1-20.

Arau, A. (productor y director). (1992). Como agua para chocolate [cinta cinematográfica]. México: Miramax.

Baumgartner, K., Friedel, C. (productores) y Nettlebek, S. (directora). (2011). Deliciosa Martha [cinta cinematográfica]. Italia: Bavaria Film International.

Betzer, J., Christensen, B., Korzen, B., Siesbye, P. (producción) y Axel, G. (director) (1987). El festín de Babette [cinta cinematográfica]. Dinamarca: Nordisk Films.

Bordwell, D. (1996). La narración en el cine de ficción. Buenos Aires: Paidós

Bote, S. (2011). Celuloide para gourmets. La Vanguardia. Recuperado de: http://www.lavanguardia.com/estilos-de-vi$\mathrm{da} / 20111014 / 54229808264 /$ celuloide-para-gourmets.html

Casetti, F. (2000). Teorías de cine. Madrid: Cátedra.

Chaplin, C. (productor y director). (1936). Tiempos modernos [cinta cinematográfica]. Estados Unidos: Charles Chaplin Productions.

Cobo, S. (2015). Modelo de análisis de estructuras narrativas en el cine de no-ficción. Un análisis filmográfico del realizador Ross McElwee. España: Universidad de Sevilla.

Contreras, J., y Gracia, M. (2005). Alimentación y cultura. Barcelona: Ariel.

De Garine, I. (1987). Alimentación, cultura y sociedad. El Correo de la Unesco, 5, 4-7. Recuperado de: http://unesdoc.unesco.org/ images/0007/000731/073178so.pdf

De Garine, I. (1998). Antropología de la alimentación: entre Naturaleza y Cultura. Actas del Congreso Internacional de Alimentación y Cultura. Huesca. Museo Nacional de Antropología. Museo Valenciano de Etnología. Recuperado de: http://valencianmuseumethnology.org/userfiles/file/Ernaehrung_und_Kultur.pdf

Ephron, N. (productora y directora). (2009). Julie E Julia [cinta cinematográfica]. Estados Unidos: Columbia Pictures.

Ferro, M. (1995). Historia contemporánea y cine. Barcelona: Ariel.

García, R. (2014). De Altamira a Instagram. Arte y gastronomía en imágenes o la necesidad de contar lo que comemos. Evolución de una tendencia. Actas-VI Congreso Internacional Latina de Comunicación Social. Universidad de la Laguna (Tenerife). Sociedad latina de comunicación, diciembre 2014. Recuperado de: http://www.revistalatinacs.org/14SLCS/2014_actas/138_Garcia.pdf 
Goyeneche, E. (2012). Las relaciones entre cine, cultura e historia: una perspectiva de investigación audiovisual. Palabra Clave, 15(3), 387-414.

Gracia, M. (2010). Alimentación y cultura en España: una aproximación desde la Antropología social. Physis. Revista de Saúde Coletiva, 20(2), 357-386. Recuperado de: http://www.scielo.br/pdf/physis/v20n2/a03v20n2.pdf

Hidalgo, T., Segarra. J., y Rodríguez, E. (2014). La gastronomía como temática recurrente en el cine: un recorrido cualitativo por las películas más representativas con contenido culinario. Actas VI Congreso Latina de Comunicación Social. Universidad de la Laguna (Tenerife). Sociedad Latina de Comunicación. Recuperado de: http://www.revistalatinacs.org/14SLCS/2014_actas/075_Hidalgo. pdf

Hidalgo, T., Segarra. J., y Rodríguez, E. (2016). El boom gastronómico en la gran pantalla. ¿Estamos ante un nuevo género cinematográfico? Fotocinema. Revista científica de cine y fotografía, 13, 229-248. Recuperado de: http://www.revistafotocinema.com/index. php?journal=fotocinema\&page $=$ article\&op $=$ viewFile\&path $\% 5 \mathrm{~B} \% 5 \mathrm{D}=377 \&$ path $\% 5 \mathrm{~B} \% 5 \mathrm{D}=348$

Hsu, K., Hsu, L.K., Jiang, F. (productores) y Lee, A. (director) (1994). Comer, beber, amar [cinta cinematográfica]. Taiwán: The Samuel Goldwyn Company.

Hyeon-jeong, H. (productor) y Yun-su, J. (director). (2007). El gran chef [cinta cinematográfica]. Korea: ShowEast Co Ltd.

Itami, J. (productor y director). (1985). Tampopo [cinta cinematográfica]. Japón: Masaki Tamura

Lewis, B. (productor) y Bird, B. (director). (2007). Ratatonille [cinta cinematográfica]. Estados Unidos: Walt Disney Pictures y Pixar Animation Studios.

Malle, V., Rassam, J.P. (productores) y Ferreri, M. (director). (1973). La gran comilona [cinta cinematográfica]. Francia: Mara Films.

Santamaría, A. (2016). El arte cinematográfico y el arte gastronómico: dos caminos paralelos que transitan en torno al tiempo. Fotocinema. Revista cientifica de cine y fotografía, 12, 201-220. Recuperado de: http://www.revistafotocinema.com/index.php?journal=fotocinema\&page $=$ article\&op $=$ view $\&$ path $\% 5 \mathrm{~B} \% 5 \mathrm{D}=354 \&$ path $\% 5 \mathrm{~B} \% 5 \mathrm{D}=293$

Silberman, S. (productor) y Buñuel, L. (director). (1972). El discreto encanto de la burguesía [cinta cinematográfica]. Francia: Greenwich Film Productions

1 Un tipo de tortuga china de caparazón blando, típico de los países asiáticos. 